\title{
Information Processing and
} Decision-Making in Pathological Worriers and their Potential Role in Mechanisms of Generalized Anxiety Disorder

\author{
Jacek Gierus \\ Faculty of Psychology, University of Economics and Human Sciences in Warsaw
}

ABSTRACT

Systematic information processing and decision-making under uncertainty are key constructs of new conceptions explaining the severity of pathological worry. The current study attempted to analyze their usefulness in subclinical and clinical groups. In the first phase of the study $(N=251)$ participants were examined with the Penn State Worry Questionnaire (PSWQ), a GP consultationrelated survey, and a screening survey for generalized anxiety disorder (GAD). In the second phase $(\mathrm{N}=220)$, the State-Trait Anxiety Inventory, the PSWQ, and tasks measuring systematic information processing (SIP) versus heuristic reasoning (HR) were applied. In the third phase (N=60), GAD ( $n$ $=30)$ and healthy control $(n=30)$ groups were examined with the above methods and the lowa Gambling Task (IGT). In the low risk group, a relationship between mood and the representativeness heuristic $(\rho=0.50$ ), as well as anchoring and adjustment heuristic (anxiety-related stimuli) was found ( $\rho=-0.53$ ). In the GAD group, significant correlations between the PSWQ score, the IGT loss avoidance score $(\rho=0.40)$, and total IGT score $(\rho=0.48)$ were found. The results did not confirm a particular usefulness of the systematic/heuristic information processing construct in subclinical and clinical groups. Theory-consistent results were rather found in the nonclinical groups. Nevertheless, the data revealed some interesting findings supporting potential explanatory power of some theoretical models.

\section{KEYWORDS}

pathological worry

generalized anxiety disorder

decision making

\section{INTRODUCTION}

Worry is described as a dynamic narrative process in which specific plots are introduced and carefully developed by the cognitive system. With its support, a person can have a complicated, internal monologue using words, abstract ideas and images. It is not assumed that they only appear as a result of negative thoughts, though most definitions usually emphasize the relation between worry and persistent awareness of some future negative event (Gladstone \& Parker, 2003).

One of the most commonly used definitions originates from Borkovec's model, in which worry is considered a chain of thoughts and images that are negatively affect-laden and relatively uncontrollable. It represents an attempt to engage in mental problem-solving of an issue whose outcome is uncertain but which contains the possibility of one or more negative outcomes (Borkovec et al., 1983).

The most important among the recently created concepts addresses the function of worry, which appears to be crucial in understanding why this phenomenon continues as well as why it can potentially lead to some emotional difficulties.
Recent ideas emphasize especially the role of worry (a) as an avoidance of emotional contrast, (b) as a repetitive information processing resulting from an increased certainty threshold in the decision-making process, and (c) as an ineffective use of executive functions.

\section{Worry as an Avoidance of Emotional Contrast}

The first derives from a research trend that emphasizes the role of worry as an anxiety suppressor. These studies have shown that initiation of the worry process enables avoidance of unpleasant emotions, images, and anticipations (Bergman \& Craske, 2000; Borkovec \& Inz, 1990; Borkovec \& Roemer, 1995; Borkovec et al., 1998; Bourne, 2011; Huang et al., 2009; Lyonfields et al., 1995; Sibrava \& Borkovec, 2006). However,

Corresponding author: Jacek Gierus, Faculty of Psychology, University of Economics and Human Sciences in Warsaw, Okopowa 59, 01-043 Warsaw, Poland. E-mail:j.gierus@vizja.pl 
there have been some interesting reinterpretations of the mentioned data. Newman and Llera (2011, see also Llera \& Newman, 2010), the authors of the contrast avoidance model, undertook a critical analysis of this trend. The authors assumed that persons with generalized anxiety disorder (GAD) are excessively sensitive to negative emotional shifts and deploy worry to decrease the difference between baseline negativity and a shifting state. According to the researchers, worry triggers a whole range of negative emotions. It is thus difficult to treat it as a useful tool for avoidance, as the other concepts suggest. This would mean that emotion avoidance and emotion processing avoidance are two completely different processes characterized by different traits and functions. As mentioned previously, Newman and Llera's studies suggest that worry does not enable negative emotion avoidance per se. Emotional processing should take place on two levels: subjective and physiological. If the process does not take place on each of these levels, or if it is hindered on either of them, emotional processing cannot be successful, and habituation is impossible. As such, worry prevents flexible responsiveness to sadness- and anxiety-inducing stimuli, suggesting a less adaptive response of the autonomous system to emotional stimuli in people with strong worry patterns. Uncontrolled concerns can thus cause prolonged anxiety and depressive states.

\section{Worry as Repetitive Information Processing Resulting from an Increased Certainty Threshold}

The second research trend mostly refers to information processing and decision theories. Early studies (Vasey \& Borkovec, 1992) suggested that the difference in catastrophizing between people who do and do not display worry thoughts may reflect an increased ability of the latter to draw from memory when attempting to answer the question: "What if...?”. Researchers became increasingly interested in people's difficulties in stopping those attempts. Problematic severity of worry has been associated with uncontrolled processing, and when people are not satisfied with a single answer to the "What if...?" question, perpetuating the process. The study by Martin et al. (1993) on mood as an input to stopping initiated tasks revealed that intermediary factors between a specific mood and stopping a task are the so-called "stop rules." People with a lowered mood using the "I feel I do not want to continue" rule would stop their tasks earlier than subjects with a lowered mood using the "I will do as much as possible" rule. People in a good mood using the "I feel I do not want to continue" rule would stop their tasks later than subjects in a good mood using the "I will do as much as possible" rule. This can be explained according to the previous example - the participants' moods informed them about their level of satisfaction with a task. The rule that was then discovered was used to explain the perseverance of worry. According to the mood-as-input hypotheses, people with a lowered mood using the "I will do as much as possible rule" tend to persevere similar to people in a good mood using the "I feel I do not want to continue" rule.

Davey (2006) applied the results of the study to his own research and assumed that subjects who worry often experience a lowered mood and use the "I will do as much as possible" rule rather strictly when de- ciding to stop catastrophizing. Researchers began to associate stopping worry and its characteristics with systematic information processing, and this, in turn, has its association with decision and information processing theories. The question of systematic and heuristic information processing was holistically covered by Chaiken's (1980) theory. According to this theory, there are two basic, competitive types of information processing: systematic and heuristic. Whenever low mood appears, people tend to use systematic information processing, which is understood as "analytical orientation, where the receiver verifies and evaluates data according to its relevance and significance integrating all the useful information through formulating a judgment" (Chaiken, 1980; Martin et al., 1993). The heuristic trend appears to be based rather on pre-existing knowledge structures (stored in the long-term memory) than on analysis of current data. Such processing requires less cognitive effort and results in quicker decision making. However, it is more prone to distortion and cognitive errors. (Kahneman, 2012). In the reference literature (Chaiken, 1980, Todorov et al., 2002), this is called analytical orientation, in which a person evaluates and analyzes the received information as a whole in terms of its (a) meaning and (b) significance, and integrates all useful information in the formulated judgments. Personal significance is crucial in this concept since algorithmic thinking depends on the way the subject assesses the level of certainty needed for deduction. If the subject says "I do not need high certainty," heuristic thinking is triggered, while when high certainty is required-algorithmic thinking (systematic information processing) is triggered. Thus, easy tasks trigger heuristic thinking, while difficult tasks trigger algorithmic thinking. In the heuristic-systematic model, the construct of a certainty threshold that determines the exchange between cognitive control and a task's goals is also important. People become engaged in cognitive effort until they reach the threshold level of certainty regarding task completion (Chaiken, 1980). One cannot be entirely sure that a judgment is correct. Nevertheless, some level of certainty can still be achieved.

Among heuristic thinking types, Kahneman (2012) mentions the following: (a) availability, (b) representativeness, and (c) anchoring and adjustment heuristics. The availability heuristic describes tendency to attach greater likelihood to events that are more available to awareness and more emotionally charged. For example, if we read two lists of people with men's and women's names mixed up in equal proportions, but one of the lists includes the names of well-known women, the participants will have the impression that the list contains more women's names. This impression is caused by the greater availability of these memory traces. The representativeness heuristic relies on a shortened way of deduction in which events are classified based on their partial similarity to a typical or a well-known case. A typical task that demonstrates this heuristic involves presenting participants with a certain feature that matches a stereotype, for example, "John is an eloquent, well-educated, and competitive man with two children. His hobby is collecting rare books. What is the likelihood of John being a lawyer rather than an engineer?" It is easy to notice that people will tend to ignore sociological statistics based on some rather stereotypical information included in the task. The anchoring and adjustment heuristic is 
a tendency to rely on some information (anchoring) and then modify it in order to formulate a judgment. An example of this heuristic is giving a distorted answer to a request to estimate some size. When an experimenter (more or less consciously) provides participants with some reference framework, they tend to "anchor" their estimations according to this framework. For example, if we ask participants how many African countries belong to United Nations and then ask one group if it is more or less than 20 and the second group if it is more or less than 30 , the estimations in the first group will be close to 20 , and those in the second one will be close to 30 . All these ways of thinking lead to quicker decision making. However, they are prone to cognitive error risk.

Inspired by the heuristic-systematic model, Dash and Davey (2012) have developed an interesting, simple cognitive model explaining the rule of initiating and sustaining the process of pathological thinking. According to this model, there is a factor that precedes and sustains worry in people who worry pathologically-their previously lowered mood. Mood can trigger worry through the previously mentioned stop rules as well as directly through shifting the threshold of accepted uncertainty. The authors quote the results of their own study, which found that lowered mood prompted participants to use systematic information processing while neglecting heuristic processing. The data they obtained proved that systematic information processing fully explains the relation between mood and intensity of pathological worry (Dash \& Davey, 2012)

\section{Worry as Repetitive Information Processing Resulting from an Increased Certainty Threshold}

The third mentioned research trend is focused on the degree of pathological worry development that can be influenced by the nonadaptive use of executive functions. Some studies based on processing efficiency theory (Eysenck \& Calvo, 1992) have attempted to establish whether worry impairs processing efficiency or if the efficiency in completing a memory task will remain undisturbed. The results were the opposite of what was expected: Worry can increase the level of task efficiency in people with a high level of anxiety and in those in whom the state of increased worry had been induced by tasks requiring engagement of verbal and spatial working memory. In other words, there is a possibility that worry may foster adaptation in cases of specific tasks. However, a person should either be used to worry and anxiety, or worry is interim and connected to a given task. Can we then conclude that containing interim benefits for potential future benefits is associated with any permanent, proven neuropsychological characteristics? The results of the studies on the role of inhibitory control in GAD are not clear. Price and Mohlman (2007), who examined GAD patients, concluded that more beneficial results in inhibitory control were associated with a higher level of symptoms, including worry and trait anxiety. No relationship between inhibitory control and the levels of anxiety and depression was found. The discovered relationship was not found in the control group. Simultaneously, patients and participants from the control group did not differ significantly in terms of the results on the
Stroop test. The researchers concluded that positive relations between inhibitory control and the level of symptoms result from nonadaptive use of executive functions. The conclusions obtained in the mentioned studies were partially confirmed by Elderth's (2008) research one year later. The researcher, who examined GAD patients, came to the conclusion that the prefrontal cortex (PFC) is more engaged in inhibiting the emotional processing area (amygdala, hippocampus). However, more severe symptoms and greater inhibitory control did not influence the brain's activity during worry (examined by magnetic resonance imaging). Only elderly patients participated in the studies. In later studies by Price et al. (2011), who used the Stroop test and functional magnetic resonance imaging, among other tests, elderly GAD patients displayed attention deficits in top-down processing, while inhibitory control deficits were not a generalized GAD trait in elderly patients; they only occur when negative emotional content "competes" for information processing resources. This could suggest that the core of potential attention deficits in some patients is the "taking over" of cognitive resources by uncontrolled concerns.

Some of the abovementioned conclusions do not stand in confrontation with chosen processing efficiency theory (PET) studies (Eysenck \& Derakshan, 2011). To date, in light of this model, it has been assumed that anxiety causes inhibitory and switching function deficits. Some authors (see Eysenck \& Derakshan, 2011) think differently: There are some special conditions in which this assumption does not reflect reality. After reviewing various studies, researchers have suggested that there are two possible ways that anxiety influences attention control. Anxiety can be related to lowered migration of attention control resources or to a noticeable (yet ineffective) migration of these resources. The first way is more likely in cases of lower motivation (nondemanding tasks, lack of relevant goals), while the second one is possible under highly motivational conditions (demanding tasks, clear goals). It appears that the particular function's efficiency is less important than the way in which it is used.

The abovementioned concepts create a relatively coherent yet questionable image. A person dissatisfied with the result of their own development of a threatening task begins to perpetuate their thinking process. Most likely, it happens either because their mood has been lowered or because they are using a perfectionist strategy to stop a task. The data analysis process that they use is precise and can be associated with systematic information processing. This brings to mind evolutionary aspects of environmental adaptation: using executive functions to solve a problem. However, this process, is not successful because the process itself begins to serve significant functions for the organism: It allows the organism to obtain tangible benefits and avoid certain type of arousal.

The consistency of the above image does not, however, change the fact we do not know whether the mechanisms are related to the general population and to clinical groups with generalized anxiety. The current study attempts to answer the following questions: (a) Do people with GAD differ from healthy controls in their preferences of using systematic information processing? (b) Do information processing styles depend on decision making under uncertainty and on the use 
of executive functions? (c) What are the relations among information processing styles, decision-making styles, and anxiety and worry?

It was hypothesized that anxiety (both state and trait) and mood would be related to deployment of systematic information processing (SIP). We can also expect significant relationship of SIP with lost avoidance and inhibitory control. However, it remains unclear how these relationships express themselves in clinical and nonclinical contexts. To answer these questions, a three-phase study has been designed.

\section{METHODS}

\section{Participants}

Participants were recruited on the researchonline.pl Internet service. The service provides an opportunity to conduct research on 2000 demographically verified Polish participants from different age groups. This fact, as well as low costs, were the key reasons for the researchers' choice of this recruitment method

All data were gathered online. The sample consisted of 471 individuals (271 females and 200 males). In the first phase of the study, participants $(N=251 ; 146$ females and 105 males, aged 18-85, $M=$ $40.2, S D=11.48)$ responded to questionnaires regarding symptoms of anxiety, depression, and pathological worry, as well as to the GAD criteria survey. In the second phase, a new participant sample $(N=220$; 125 females and 95 males, aged 19-71, $\mathrm{M}=41.2, S D=10.98$ ) was also asked to take part in systematic information processing/heuristic reasoning (SIP/HR) tasks and measures of depression and GAD-related symptomatology. In the third phase, participants were recruited from the two previous phases: The psychiatrist contacted (alphabetically, by phone) those subjects who either expressed high levels of state-trait anxiety and worry or reported no life psychiatric symptomatology. Phone interviews were conducted to recruit a third-phase sample of participants from the first and second phases. Subjects who had reported high levels of worry and anxiety and had confirmed symptomatology in a survey were further interviewed by phone. The psychiatrist conducted an ICD-10 criteria-based interview and checked participants for possible comorbid disorders. Participants were divided in two groups: a GAD group ( $n=30$, aged $18-62, M=40.1, S D=11.77)$ and a control group $(n=30$, aged 24-67, $M=39.1, S D=9.99)$ based on the ICD-10 criteria. In the third phase, subjects were examined with the Iowa Gambling Task posted on psytoolkit.org (Stoet, 2010, 2017), which is an experimental environment for online research. The local ethics committee approved the study.

\section{Measures}

\section{PENN STATE WORRY QUESTIONNAIRE}

The Penn State Worry Questionnaire (PSWQ, Meyer et al., 1990)

is a 16-item measure of worry that has been shown to have adequate internal consistency and convergent validity in patients with GAD, and it is a widely used screening instrument for GAD. The Polish adaptation authored by Janowski (2007) was used. Reliability indicators for the Polish adaptation were measured with Cronbach's $\alpha$, which ranged from .76 to .90 (Solarz \& Janowski, 2013). A cutoff point of 45 points is commonly used to identify pathological worry, and a cutoff of 62 points is used to differentiate GAD from other anxiety disorders (Clark \& Beck, 2009).

\section{STATE-TRAIT ANXIETY INVENTORY}

The State-Trait Anxiety Inventory (STAI) was originally developed by Spielberger et al. (1968). It consists of 20 items each for state and trait anxiety. The Polish version of the STAI revealed satisfactory reliability (Cronbach's $\alpha$ ranged from .83 to .92) and validity (Sosnowski et al., 2011).

\section{SIP/HR TASKS}

The tasks used to measure the use of systematic information processing versus heuristic reasoning were inspired by the experiments constructed by Tversky and Kahneman (Chaiken \& Trope, 1999; Epstein, 1994; Kahneman, 2012). The subjects were asked hypothetical questions with uncertain answers. Three types of heuristic reasoning were measured: (a) the availability heuristic, (b) the representativeness heuristic, and (c) the anchoring and adjustment heuristic. In the described study, the SIP/HR measures were implemented as described below.

Availability heuristic measurement, "neutral" version. The participants were presented with a recording of a list of 42 names of women and men that was read out loud. Within the list, some names of wellknown people were hidden. The participants' task was to estimate the number of men and women on the list. In fact, every time, the sex ratio was 50:50, but there were more well-known women than well-known men on the list. Estimation according to the number of well-known people despite the facts indicates that a person is using the availability heuristic and thus using an implicit memory in an unconscious way.

Availability heuristic measurement, "modified" version. Next, the participants were presented with another list (also with a 50:50 sex ratio). However, instead of well-known people, some of the names were preceded by an additional description. Among men, there were far more fear-inducing descriptions (e.g., "murderer", "stabber", etc.). The participants' task was to estimate the number of men and women. Deviation from 50 (in favor of men) was the measure of the availability anxiety memory trait heuristic (thus, the use of implicit memory).

Representativeness heuristic measurement, "neutral" version. The participants had to solve a specific task: "There are 70 doctors and 30 psychologists working at a hospital. Karolina is a married, hard-working person with $\mathrm{PhD}$. What is the likelihood that Karolina is a doctor?" The measure of the representativeness heuristic was the deviation of the estimated likelihood from the actual likelihood influenced by the provided information. The actual likelihood was $70 \%$. The more the participant's answer deviated from the actual likelihood, the stronger the use of the representativeness heuristic.

Representativeness heuristic measurement, "modified" version. The participants were asked to solve a task: "You are about to undergo a surgery. The surgeon has informed you that 80 out of 100 patients 
fully recover, while 20 may experience complications. You find out that the surgeon is ill, and the intern will be conducting your surgery. What are the chances you will fully recover?" The measure of the representativeness heuristic was a deviation of the estimated likelihood from the actual likelihood influenced by the "anxiety" information. The value of the deviation was the indicator of the use of the representativeness heuristic.

Anchoring and adjustment heuristic measurement, "neutral" version. The participants were given a task: "Please estimate what percentage of African countries belong to the United Nations. Do you think it is more than 20 ? How many exactly?" The result of the task was an average difference between 20 and the provided values. The tendency to be influenced by the number 20 in a given answer was the measure of the anchoring and adjustment heuristic's use.

Anchoring and adjustment heuristic measurement, "modified" version. The participants were given a task: "What is the likelihood that some of your closest family members become chronically ill? Is it more or less than $20 \%$ ? How much exactly?" The absolute value of the difference between number 20 and the values given by participants was the measure of the anchoring and adjustment heuristic.

\section{COMPUTERIZED IOWA GAMBLING TASK}

The Iowa Gambling Task (IGT, Busemeyer \& Stout, 2002; Jaracz \& Borkowska, 2012) studies decision making using cards. It is a simulation of a gambling game. In our study, the IGT was implemented in the PsyToolkit environment. The participants had to choose one out of four card decks (named A, B, C, and D). The researcher established two indicators of decision making: the percentage of "save" clicks per card and the overall financial score at the end of the game. The first parameter seemed to be a good indicator of loss avoidance, the second one seemed to be a good indicator of the effectiveness of decision making under uncertainty.

\section{STATISTICS}

The data were analyzed with Statsoft STATISTICA 13 and SPSS. Nonparametric Spearman's $\rho$ correlation coefficient analysis and Mann-Whitney's $U$ test of intergroup differences were performed.

\section{RESULTS}

A total of 251 (146 females and 105 males) participants aged 19-85 took part in Phase 1. Based on a normal distribution, 162 participants qualified for the medium pathological worry group, 50 for the low results group, and 39 (15.5\%) for the high results group. The mean result on the PSWQ scale was $49.76(S D=12,97)$.

A total of 220 participants (125 females and 95 males) took part in the second phase of the study with the use of an Internet panel. The average age in the sample was 41.2 years (19-71 years). The average PSWQ result was $49.99(S D=13.9)$. The results of the mood self-assessment can also be interpreted as average, $M=6.35, S D=1.91$. State anxiety $(M=39.5, S D=10.99)$ and trait anxiety $(M=45.5, S D=9.54)$ in the studied group scored average results according to the norms.
The studied group did not differ significantly from the normalization groups in terms of the parameters of the used methods. Two extreme groups were selected (each including 30 participants). Subjects meeting the GAD criteria (based on self-assessment) and those with the highest level of worry were included in the high-risk group (HR), while participants who did not match the GAD criteria and those with lowest scores on the PSWQ were included in the low-risk group (LR). The two subgroups did not differ in terms of age. While the sex ratio was rather equal in the LR group, there were far more females in the HR group $(n=22)$, which does not seem surprising in the light of the subject literature.

There were, however, some expected and obvious (considering the created subgroups) differences in terms of worry intensity $(U=0.00, p$ $=.00)$, state anxiety $(U=234, p=.00)$ and trait anxiety $(U=198, p=$ $.00)$. All or most of the values were higher in the HR group in terms of worry and anxiety, which was a consequence of the method of subdivision of the sample. Additionally, there was a small yet significant intergroup difference in terms of the mood declared at the time of the study ( $U=288, p=0,01$ ). It is not surprising that participants in the HR group assessed their mood as lower than those in the LR group.

The sex ratio in the sample in the third phase was 28 to $32(46 \%$ to $53 \%)$. Similar to the second phase, after dividing the extreme subgroups, the proportion of men and women changed significantly. In the GAD group, there were significantly more women (70\% to $30 \%$, 21 to 9$)$, while in the control group, there were more men $(63.3 \%$ to $36.6 \% ; 19$ to 11$)$. The subgroups did not differ significantly in terms of age $(U=416, p=.61)$. However, some significant differences were discovered in terms of state anxiety $(U=124, p=.00)$, trait anxiety $(U$ $=127.5, p=.00)$, and $\operatorname{mood}(U=211.5, p=.00)$, and there were borderline significant differences in terms of worry intensity $(U=329.5, p$ $=.07)$. Because the difference between the average PSWQ scores was 6 raw points, it can be argued that in larger groups this difference would have been unambiguously significant. The subgroup creation criteria caused an unsurprising trend in the results in terms of intergroup differences. The GAD group was characterized by a higher tendency to have anxiety reactions and a higher level of anxiety during the study. Participants in this group reported a significantly lower mood and worried more than those in the control group.

\section{Phase 1}

The first phase of the study revealed that $12 \%$ of the sample $(N=251)$ reported symptoms meeting the GAD criteria during the study survey, while $30 \%$ declared meeting the GAD criteria over their lifetime. After a detailed ICD-10-based phone-interview, the percentage of subjects who were qualified for inclusion in the confirmed GAD group decreased to $4.7 \%(n=12)$. Among subjects with confirmed GAD, only $30 \%$ were psychometrically high worriers (subjects who scored $>62$ points on the PSWQ).

In the studied group, the majority of participants (71\%) were people who saw their GPs between once a month and once a year. A total of 192 participants from the group saw their GPs with such frequency. A significant (almost half) of the studied group had declared suffering 
TABLE 1.

High Risk and Low Risk Groups_Descriptive Statistics

\begin{tabular}{lcccc}
\hline \multicolumn{5}{c}{ High risk group descriptive statistics } \\
\hline Variable & $M$ & $S D$ & Min. & Max. \\
\hline PSWQ & 63.56 & 7.69 & 52 & 80 \\
Mood & 5.13 & 1.94 & 2 & 10 \\
STAI state anxiety & 49.20 & 10.76 & 32 & 71 \\
STAI trait anxiety & 55.03 & 6.25 & 46 & 69 \\
\hline \multicolumn{5}{c}{ Low risk group descriptive statistics } \\
\hline PSWQ & 29.90 & 5.73 & 18 & 37 \\
Mood & 6.43 & 1.81 & 3 & 10 \\
STAI state anxiety & 38.60 & 11.85 & 22 & 65 \\
STAI trait anxiety & 43.26 & 12.20 & 27 & 71 \\
\hline
\end{tabular}

from a chronic disease. Considering the possible distortions caused by the confounding variable (long-term anxiety and lowered quality of life), it was decided to perform some of the analyses in two ways: with the entire sample $(N=251)$ and with the sample excluding the chronically ill participants $(N=140)$. Over a half of the studied sample had confirmed a situation in which they checked with their doctor because of symptoms that did not have a somatic cause. The way the question was asked made it possible for those with anxiety disorder symptoms and for those undergoing diagnosis of a somatic disease to be included in the group. Despite this, almost the same number of participants in the studied group confirmed that after seeing their doctors, they received information that an anxiety disorder was the cause of the declared symptoms. In half of these patients, further consultations and tests were suggested. Approximately 1/5 of the studied group was further examined. A similar number of participants received sedative prescriptions as a result of a doctor's consultation. The percentage of people meeting the GAD criteria and simultaneously experiencing increased worry was $12 \%$. However, it should be taken into account that similar symptoms may have been reported by patients with different psychiatric disorders or patients with comorbidities.

\section{Phase 2}

To further verify the hypotheses, data from the second sample $(N=$ 220) were analyzed. The researchers also selected two subgroups denoted as the LR and HR groups. The LR $(n=30)$ group was created by selecting 30 subjects with the lowest PSWQ scores who also did not meet the GAD criteria. The HR $(n=30)$ group was selected from among subjects who met the GAD criteria and scored the highest scores on the PSWQ. Among the LR group subjects, 53\% were males, while the HR group mainly consisted of females (73.3\%).

The results of the correlational analysis of the whole sample $(N=$ 220) revealed only small relationships between anxiety and SIP/HR. State anxiety was correlated with the anchoring and adjustment heuristic $(\rho=.14, p<.05)$ and the availability heuristic $(\rho=.17, p<.05)$. Trait anxiety was revealed to have a small correlation $(\rho=.14, p<.05)$ with the availability heuristic. The anchoring and adjustment heuristic were significantly correlated with $\operatorname{mood}(\rho=.15, p<.05)$.

In the LR group, state anxiety was significantly related to the anchoring and adjustment heuristic (0.42), while mood displayed a relationship with the representativeness heuristic $(0.50)$ and anchoring and adjustment heuristic (anxiety-related stimuli, $-0.53, p<.05$ ). The HR and LR groups did not differ significantly in terms of SIP/HR. However, the LR group presented a significantly better $(U=288$, $p=$ .02) mood than the HR group.

\section{Phase 3}

In the third phase of the study, data from the GAD group $(n=30)$ and the control group (controls, $n=30$ ) were analyzed. The GAD group did not differ from the control group in terms of SIP/HR or IGT scores. Women reported significantly higher levels of worry $(M=48.90)$ than men $(M=41.75), U=312.50, p=.04)$.

In the control group, a significant correlation $(\rho=-.37, p<.05)$ between mood and the anchoring and adjustment heuristic was found. In the GAD group, correlations were found between the PSWQ score and the IGT including the IGT loss avoidance score $(\rho=.40, p<.05)$ and total IGT (decision effectiveness) scores $(\rho=.48, p<.05)$. The re-

TABLE 2.

Generalized Anxiety Disorder and Healthy Controls—Descriptive Statistics

\begin{tabular}{|c|c|c|c|c|}
\hline \multicolumn{5}{|c|}{ Generalized anxiety disorder group descriptive statistics } \\
\hline Variable & $M$ & $S D$ & Min. & Max. \\
\hline PSWQ & 48.73 & 15.52 & 19 & 78 \\
\hline Mood & 5.31 & 1.64 & 2 & 9 \\
\hline STAI state anxiety & 48.00 & 10.53 & 25 & 68 \\
\hline STAI trait anxiety & 52.66 & 8.71 & 34 & 72 \\
\hline $\begin{array}{l}\text { SIP/HR representativeness } \\
\text { neutral }\end{array}$ & 12.55 & 17.69 & 0 & 69 \\
\hline $\begin{array}{l}\text { SIP/HR representativeness } \\
\text { emotional }\end{array}$ & 23.68 & 22.83 & 0 & 60 \\
\hline $\begin{array}{l}\text { SIP/HR anchoring \& } \\
\text { adjustment neutral }\end{array}$ & 13.13 & 10.63 & 0 & 40 \\
\hline $\begin{array}{l}\text { SIP/HR anchoring \& } \\
\text { adjustment emotional }\end{array}$ & 25.55 & 21.34 & 0 & 80 \\
\hline SIP/HR Availability neutral & 4.7 & 7.1 & 0 & 29 \\
\hline SIP/HR Availability emotional & 2.66 & 3.57 & 0 & 17 \\
\hline IGT loss avoidance & 57.96 & 17.52 & 32 & 100 \\
\hline Stroop B task time [ms] & 51577.20 & 14349.64 & 24580 & 89000 \\
\hline \multicolumn{5}{|c|}{ Healthy control group descriptive statistics } \\
\hline PSWQ & 42.40 & 12.58 & 18 & 76 \\
\hline Mood & 7.10 & 1.74 & 4 & 10 \\
\hline STAI state anxiety & 33.36 & 7.76 & 20 & 49 \\
\hline STAI trait anxiety & 39.46 & 8.57 & 25 & 56 \\
\hline $\begin{array}{l}\text { SIP/HR representativeness } \\
\text { neutral }\end{array}$ & 16.89 & 19.03 & 0 & 69 \\
\hline $\begin{array}{l}\text { SIP/HR representativeness } \\
\text { emotional }\end{array}$ & 17.93 & 21.27 & 0 & 60 \\
\hline $\begin{array}{l}\text { SIP/HR anchoring \& } \\
\text { adjustment neutral }\end{array}$ & 12.20 & 14.91 & 0 & 80 \\
\hline $\begin{array}{l}\text { SIP/HR anchoring \& } \\
\text { adjustment emotional }\end{array}$ & 19.80 & 18.02 & 0 & 80 \\
\hline SIP/HR Availability neutral & 7.10 & 8.74 & 0 & 29 \\
\hline SIP/HR Availability emotional & 4.9 & 6.35 & 0 & 29 \\
\hline IGT loss avoidance & 52.90 & 20.15 & 11 & 99 \\
\hline Stroop B task time [ms] & 50958.30 & 7974.28 & 35916 & 73680 \\
\hline
\end{tabular}



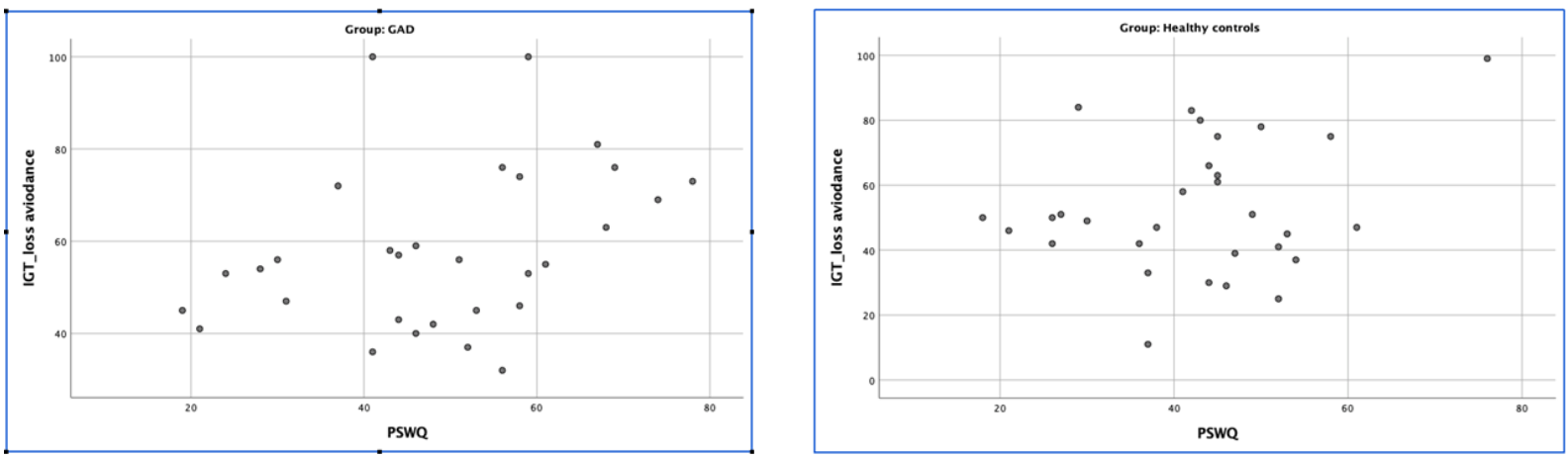

FIGURE 1.

Relationship between lowa Gambling Task loss avoidance and Penn State Worry Questionnaire score in generalized anxiety disorder and healthy controls groups.

lationship between loss avoidance and the level of pathological worry was visually more linear in the GAD group, as presented in Figure 1.

Men and women did not differ in terms of IGT loss avoidance and IGT decision effectiveness. However, observations in men were more scattered, while in women, they tended to be more linear. No significant differences between the clinical and control groups were found in terms of the Stroop B Task.

\section{DISCUSSION}

The results of the presented study appear far more complex than the research questions would suggest. The answer to a question whether people with generalized anxiety differ in their preference to use systematic information processing from healthy individuals is not clear. No significant intergroup differences have been discovered, there have been, however, several relationships that would require further thought. First of all, subjects with high level of worry scored higher in the gambling game simulation. This would suggest that a clinical increase in symptoms is associated with loss avoidance under uncertainty and in turns using more cautious decision styles. It seems that this part of the research is coherent both with Newman and Llera's (2011, see also Llera \& Newman, 2010) contrast avoidance model and Dash and Davey's (2012) model regarding shifted certainty threshold. The core of gambling is decision making under uncertainty. Thus, people who worry more make more cautious decisions. This relationship is visible particularly in clinical group. High level of worry might be helpful in avoiding potential loss, while Newman and Llera (2011, see also Llera \& Newman, 2010) claim it can help avoid negative emotional contrast. Emotional contrast can be then identified with punishment related to loss. Data indicated also that there were no differences between clinical and control group in terms of deployment of SIP/HR. Relationships between SIP/HR and worrisome activity revealed in nonclinical groups, which means that outcomes presented by Dash and Davey (deployment of SIP related to worry) are probably limited to nonclinical groups. It can be concluded with caution that it is in fact a function of worry that can be associated with specific adjustment benefits. However, if we consider a broader cultural context, this benefit is debatable. Previous research did not indicate any detrimental impact of worry on memory tasks (Eysenck \& Calvo, 1992, Walkenhorst \&
Crowe, 2009). The relationship between worry and executive functioning is probably more complex. While in general, GAD subjects present similar performance in Stroop Tasks (see also Eldreth, 2008, Price et al., 2011), they score better in terms of avoiding long-term losses in the IGT (see also Mueller et al., 2010). The current study can support Eldreth's (2008, Price et al., 2011) outcomes, which connected intergroup differences more with the way executive functions are "used", than with their level per se.

In the nonclinical groups, some interesting relationships have also been found. Subjects experiencing state anxiety are more likely to trigger SIP. However, this cannot be said about people who are generally more anxious (high trait anxiety). These participants, in turn, tend to overestimate the likelihood of negative events and they use heuristic reasoning, especially the representativeness heuristic. It happens while facing an anxiety-inducing content. When confronted with anxiety, their cognitive system tends to shorten the reasoning process rather than make an analytical effort. Healthy controls in good mood were less likely to make a systematic information processing effort-they would rather use the anchoring and adjustment heuristic. In other words-they were more suggestive. Lower moods, in turn, caused their greater tendency to use availability heuristic, meaning unconscious use of one's memory. In the HR group, worry was strongly connected only with anxiety intensity and mood. The results obtained in the SIP/HR suggest, then, that while anxiety intensity and mood are related with the use of algorithms versus heuristics, these results cannot be directly extrapolated to subclinical and clinical groups. Nevertheless, the issue of decision-making is still important in these groups. However, it is likely that the older concept of mood as trigger (Davey, 1983) would be more useful in explaining the processes happening in these groups than the model that treats worry as SIP (Dash \& Davey, 2012).

The question whether information processing styles are related with decision-making under uncertainty and with the use of executive functions has already been partially answered-there appears to be no relation. The only significant correlation was found in the second and the third phases of the study. People who used the representativeness heuristic also scored higher in the Stroop B task. This might suggest that when participants from the subclinical and clinical groups are part of the study, some of these participants might have a tendency to 
use systematic information processing as a result of difficulties in executive functions. Taking Elderth's (2008) research into consideration, one could conclude that this is not what could have been expected. However, one could cautiously make a hypothesis that SIP and pathological worry are not necessarily the same thing: Attention deficits may also lead to using heuristics and neglecting SIP.

When answering the third research question, it can be said that anxiety and worry show some correlations with SIP/HR and decisionmaking under uncertainty. First, worry is related with better results and more cautious decisions in gambling, but this has been proven only for the clinical GAD group. Second, anxiety revealed correlations with the anchoring and adjustment heuristic, but only in the LR group. In the HR and clinical groups, those factors correlated mainly with the mood.

The third phase of the study brought data about the clinical context of postulated questions. First, GAD subjects do not differ from healthy controls in use of systematic information processing and heuristics. Second, the level of pathological worry in this group is significantly related to deployment of loss avoidance measured with a method that actually is a test for executive function. To sum up, it can be hypothesized that in the clinical context, pathological worry is related to usage of executive functions in very specific way: to avoid anticipated losses. These results can support outcomes presented by Eldreth (2008; Price et al., 2011).

The presented studies' results are not free from a number of flaws. First of all, the majority of women in the GAD population was not taken into account when selecting the sample, which could have been anticipated. Thus, the results of the third phase cannot be generalized to men. Women make more cautious decisions, but they also suffer from anxiety and depressive disorders more often. It can be connected with the fact that men are more easily excused for their impulsiveness, while women are brought up to make careful decisions (Braverman, 2006). Second, the completion of some tasks with the use of a remote computer study remains debatable. Despite controlling the data quality, there could have been some significant distortions, especially in the Stroop B task. Third, the correlation model limits the ways of data analysis. Thus, in future, it would be worth to carry a study with a similar methodology on a group several times bigger, as this would enable the use of multivariate analysis.

To summarize, some interesting relationships have been discovered in the current study, which, however, suggest that only the part of the mentioned theoretical approaches may be potentially applied to explain the repeatability of worry in subclinical and clinical groups. The SIP/HR construct does not seem to be particularly useful in these groups.

\section{ACKNOWLEDGEMENTS}

The author received no funding from an external source. Ethics Committee of Medical University of Warsaw approved the study. Author reports no conflicts of interest.

\section{REFERENCES}

Bergman, R. L. \& Craske, M. G. (2000). Verbalization and imagery in worry activity. Depression and Anxiety, 11, 169-174. 10.1002/1520-6394(2000)11:4<169::AID-DA4>3.0.CO;2-V 布

Borkovec, T. D, \& Inz, J. (1990). The nature of worry in generalized anxiety disorder: A predominance of thought activity. Behaviour Research And Therapy, 28, 153-158. doi: 10.1016/0005-

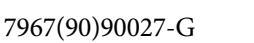

Borkovec, T. D., Ray, W. J., \& Stöber, J. S. (1998). Worry: cognitive phenomenon intimately linked to affective, psychological, and interpersonal behavioral processes. Cognitive Therapy and Research, 22, 561-576. doi: 10.1023/A:1018790003416 سلسلسل

Borkovec, T. D., \& Roemer, L. (1995). Perceived functions of worry among generalized anxiety disorder subjects: Distraction from more emotionally distressing topics? Journal of Behavior Therapy and Experimental Psychiatry, 26, 25-30. doi: 10.1016/00057916(94)00064-S الس السلس

Borkovec, T. D., Robinson, E., Pruzinsky, T., \& DePree, J. A. (1983). Preliminary exploration of worry: Some characteristics and processes. Behaviour Research and Therapy, 21, 9-16. doi: 10.1016/00057967(83)90121-3 سلس

Bourne, E.J. (2011). Lęk i fobia [Anxiety and phobia]. Wydawnictwo Uniwersytetu Jagiellońskiego.

Braverman, L. (2006). Podstawy feministycznej terapii rodzin [Basics of feminist family therapy]. GWP.

Busemeyer, J. R., \& Stout, J. C. (2002). A contribution of cognitive decision models to clinical assessment: Decomposing performance on the Bechara gambling task. Psychological Assessment, 14, 253-262. doi: 10.1037//1040-3590.14.3.253 السلسلس

Chaiken, S. (1980). Heuristic versus systematic information processing and the use of source versus message cues in persuasion. Journal of Personality and Social Psychology, 39, 752-766. doi: 10.1037/00223514.39.5.752 سلس

Chaiken, S., \& Trope, Y. (1999). Dual-process theories in social psychology. The Guilford Press.

Clark, D. A., \& Beck, A. T. (2009). Cognitive assessment and case formulation. In D. A. Clark, \& A. T. Beck (Eds.), Cognitive therapy of anxiety disorders. Science and practise (pp. 127-179). Guilford Press.

Dash, S. R., \& Davey, G. C. L. (2012). An experimental investigation of the role of negative mood in worry: The role of appraisals that facilitate systematic information processing. Journal of Behavior Therapy and Experimental Psychiatry, 43, 823-831. doi: 10.1016/j. jbtep.2011.12.002 السلسلس

Davey G. C. L. (2006). A mood-as-input account of perseverative worrying. In G.C.L. Davey, \& A. Wells (Eds.), Worry and its psychological disorders. Theory, assessment and treatment (pp. 217-238). Wiley \& Sons.

Eldreth, D. A. (2008). The neural substrates of worry in older adults with generalized anxiety disorder. Dissertation Abstracts International, 69(8-B), 5021.

Epstein, S. (1994). Integration of the cognitive and the psychodynamic unconscious. American Psychologist, 49, 709-724. doi: 


\subsection{7/0003-066x.49.8.709 Шلس}

Eysenck, M. W., \& Calvo, M. G. (1992). Anxiety and performance: The processing efficiency theory. Cognition and Emotion, 6, 409-434.

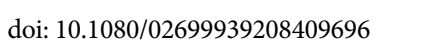

Eysenck M. W., \& Derakshan N. (2011). New perspectives in attentional control theory. Personality and Individual Differences, 50, 955-960. doi: 10.1016/j.paid.2010.08.019 سلس

Gladstone, G., \& Parker, G. (2003). What's the use of worrying? Its function and its dysfunction. Australian and New Zealand Journal of Psychiatry, 37, 347-354. doi: 10.1046/j.0000-0000.2003.01187.x المالسلسل|

Huang K., Szabó M., \& Han J. (2009). The relationship of low distress tolerance to excessive worrying and cognitive avoidance. Behaviour Change, 26, 223-234. الس الس

Janowski, K. (2007). Kwestionariusz Oceny Martwienia się, polska adaptacja PSWQ [The PSWQ worry questionnaire. Polish adaptation]. Wydawnictwo KUL.

Jaracz, M., \& Borkowska, A. (2012). Iowa Gambling Task-tool for assessment of decision making. Psychiatria Polska, 46, 461-472.

Kahneman, D. (2012). Pułapki myślenia. O myśleniu szybkim i wolnym [Thinking, fast and slow]. Media Rodzina.

Llera, S. J., \& Newman, M. G. (2010). Worry and emotional avoidance in generalized anxiety disorder: Effects on physiological and subjective reactivity. Emotion, 10, 640-650. doi: 10.1037/a0019351 المبلسلبل

Lyonfields, J. D., Borkovec, T. D., \& Thayer, J. F. (1995). Vagal tone in generalized anxiety disorder and the effects of aversive imagery and worrisome thinking. Behavior Therapy, 26, 457-466. doi: 10.1016/ S0005-7894(05)80094-2 المالس

Martin, L. L., Ward, D. W, Achee, J. W., \& Wyer, R. S. (1993). Mood as input: People have to interpret the motivational implications of their moods. Journal of Personality and Social Psychology, 63, 317-326. doi: 10.1037/0022-3514.64.3.317 السلسلس

Meyer, T. J., Miller, M. L., Metzger, R. L., \& Borkovec, T. D. (1990). Development and validation of the Penn State Worry Questionnaire. Behaviour Research and Therapy, 28, 487-495. doi: 10.1016/00057967(90)90135-6 السلسلس

Mueller, E. M., Nguyen, J., Ray, W. J., \& Borkovec, T. D. (2010). Futureoriented decision-making in Generalized Anxiety Disorder is evident across different versions of the Iowa Gambling Task. Journal of Behavior Therapy and Experimental Psychiatry, 41, 165-171. doi: 10.1016/j.jbtep.2009.12.002 السلسلسلس

Newman, M. G., \& Llera, S. J. (2011). A novel theory of experiential avoidance in generalized anxiety disorder: A review and synthesis of research supporting a contrast avoidance model of worry. Clinical Psychology Review, 31, 371-382. doi: 10.1016/j.cpr.2011.01.008 المالسلسل| Price, R. B., Eldreth, D. A., \& Mohlman, J. (2011). Deficient prefrontal at- tentional control in late-life generalized anxiety disorder: An fMRI investigation. Translational Psychiatry, 1, e46. doi: 10.1038/tp.2011.46 البلسلسلة Price, R. B., \& Mohlman, J. (2007). Inhibitory control and symptom severity in late life generalized anxiety disorder. Behavior Research and Therapy, 45, 2628-2639. doi: 10.1016/j.brat.2007.06.007 الس

Ruscio, A. M., Borkovec, T. D., \& Ruscio, J. (2001). A taxometric investigation of the latent structure of worry. Journal of Abnormal Psychology, 110, 413-422. doi: 10.1037/002-843x.110.3.413 الس الس

Sibrava, N.J., \& Borkovec, T.D. (2006). The cognitive avoidance theory of worry. In G. C. L. Davey, \& A Wells (Eds.), Worry and its psychological disorders. Theory, assessment and treatment (pp. 239-258). Wiley \& Sons.

Solarz, A., \& Janowski, K. (2013). Skłonność do martwienia się, przekonania o martwieniu się a osobowość-analiza wzajemnych zależności i różnic międzypłciowych [Tendency to worry and worry beliefs and personality -analysis of relationships and gender differ-

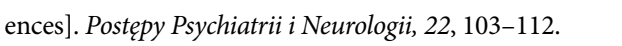

Sosnowski, T., Wrześniewski, K., Jaworowska, A., \& Fecenec, D. (2011). Inwentarz Stanu i Cechy Lęku. Polska adaptacja STAI [State-trait anxiety inventory. Polish adaptation]. Pracownia Testów Psychologicznych.

Spielberger, C. D., Gorsuch, R. L., \& Lushene, R. E. (1968). Statetrait anxiety inventory (STAI): Test manual for form $X$. Consulting Psychologists Press.

Stoet, G. (2010). Psytoolkit-A software package for programming experiments using Linux. Behavior Research Methods, 42, 1096-1104. doi: 10.3758/BRM.42.4.1096 السلسلة

Stoet, G. (2017). Psytoolkit: A novel web-based method for running online questionnaires and reaction times experiments. Teaching of Psychology, 44, 24-31. doi: 10.1177/0098628316677643 المالسلس

Todorov A., Chaiken S., \& Henderson M. D. (2002). The heuristicsystematic model of social infirmation processing. In J. P. Dillard, M. Pfau (Eds.), The persuasion handbook: Introduction (pp. 195-232). Sage.

Vasey, M. W. \& Borkovec, T. D. (1992). A catastrophizing assessment of worrisome thoughts. Cognitive Therapy and Research, 16, 505-520. doi: 10.1007/BF01175138 الم

Walkenhorst E., \& Crowe, S. (2009). The effect of state worry and trait anxiety on working memory processes in a normal sample. Anxiety,

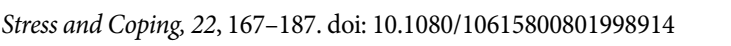

RECEIVED 22.08.2019 | ACCEPTED 19.10.2020 